\title{
A Hybrid Model Based on Fuzzy AHP and Fuzzy WASPAS for Construction Site Selection
}

\author{
Z. Turskis, E.K. Zavadskas, J. Antucheviciene, N. Kosareva
}

\author{
Zenonas Turskis, Edmundas Kazimieras Zavadskas*, \\ Jurgita Antucheviciene, Natalja Kosareva \\ Vilnius Gediminas Technical University \\ Sauletekio al. 11, LT-10223 Vilnius, Lithuania \\ zenonas.turskis@vgtu.lt, edmundas.zavadskas@vgtu.lt \\ jurgita.antucheviciene@vgtu.lt, natalja.kosareva@vgtu.lt \\ *Corresponding author: edmundas.zavadskas@vgtu.lt
}

\begin{abstract}
The purpose of this article is to propose a fuzzy multi-attribute performance measurement (MAPM) framework using the merits of both a novel Weighted Aggregated Sum-Product Assessment method with Fuzzy values (WASPAS-F) and Analytical Hierarchy Process (AHP). The object of this study is to select the best shopping centre construction site in Vilnius. A number of conflicting qualitative and quantitative attributes exist for evaluating alternative construction sites. Qualitative attributes are accompanied by ambiguities and vagueness. This makes fuzzy logic a more natural approach to this kind of multi-attribute decision making (MADM) problems. Fuzzy AHP is applied for assigning weights of the attributes and WASPAS-F method is used to determine the most suitable alternative.

Keywords: AHP, WASPAS-F, Fuzzy AHP, multi-attribute decision making (MADM), key performance attributes, construction site, shopping centre.
\end{abstract}

\section{Introduction}

The increasing competition cause a lot of construction site selection problems. Making decisions is a complex process that involves multiple, usually conflicting, objectives or attributes. They are ill-structured. Multi-criteria decision aid (MCDA, the European School) or multiattribute decision making (MADM, the American School) constitutes an advanced field of operations research which is devoted to the development and implementation of decision support methodologies to confront complex decision problems. The problem of how decisions are or ought to be taken by individuals, organisations and institutions was previously discussed by Aristotle [1]. Later, in the 18th century Bernoulli [2] concentrated research on probability theory, Borda [3] on social choice procedures. The foundations of MCDA can be traced back in the works of von Neumann and Morgenstern [4] and Fishburn [5] on utility theory. Multi-attribute utility theory (MAUT) is an extension of the classical utility theory. The theory underlying multi-attribute performance measurement models was developed in the 1960s, as summarised in Keeney and Raiffa [6] and Zeleny [7].

Most of these methods have been developed based on the concepts of accurate measurements and crisp evaluation. The performance measurement parameters cannot be given precisely. The imprecision comes from different sources: unquantifiable information, incomplete information, no obtainable information, and partial ignorance. The real-world problems in performance measurement involve numerous aspects of uncertainty, contain a mixture of fuzzy and crisp data and may have a large number of alternatives and dozens of attributes. The solution is highly dependent on the preferences of the decision maker. It is common that people may not be $100 \%$ sure when making subjective judgments. If all or some of the alternatives are imprecise, then fuzzy MADM methods are required. Zimmermann's description of uncertainty is as follows: 
Uncertainty implies that in a certain situation a person does not possess the information which quantitatively and qualitatively is appropriate to describe, prescribe or predict deterministically and numerically a system, its behaviour or other characteristics [8]. Fuzzy set theory is developed for solving problems, taking into account uncertainty, imprecision, vagueness. A pioneering and outstanding works on fuzzy sets are done by Zadeh [9] - [12]. The papers introduced a new perspective on the treatment of uncertainty, ambiguity, linguistic variables, and a fundamental aspect of formal languages: fuzzy set theory. Fuzzy measures can be introduced for two different uses: either they can represent a concept imprecisely known (although well defined) or a concept which is vaguely perceived such as in the case of a linguistic variable. The basic concepts and algorithms from classical MADM methods have been used in the development of the fuzzy MADM methods.

Fuzzy direct aggregation procedures of MADM methods generally consist of two stages:

1. The aggregation of the performance scores with respect to all attributes (goals) and per decision alternative, and

2. The rank ordering of the aggregated judgments of decision alternatives determine the optimal alternative.

Construction site selection is an important task. Proper construction site selection can improve project's success. Construction site selection for shopping centre requires a good visibility and accessibility, proper access to suppliers, customers, suitable transportation network and sufficient customer traffic and socio-economic population characteristics. The evaluation data of location performance of the construction site for various subjective attributes, and the weights of the attributes are usually expressed in linguistic terms. This makes fuzzy logic a more natural approach to this kind of problems. There is a limited number of papers evaluating suitable locations. Usually GIS in combination with decision making methods is applied for selecting the best site for ecologically and economically important objects such as renewable energy systems, including solar or wind farms [13] - [15]. Prioritizing the best sites for waste management is suggested by applying fuzzy TOPSIS [16] or VIKOR [17] methods. AHP is applied for warehouse [18] or solar farm [19] construction site selection. Also fuzzy MCDM frameworks for locating plants are suggested [20], [21]. Application of interval type-2 fuzzy sets for watershed site selection is presented [22]. Hybrid approach of fuzzy analytic network process (ANP), fuzzy DEMATEL and fuzzy ELECTRE for site selection is suggested [23].

The purpose of this article is to propose a novel fuzzy multi-attribute performance measurement framework using the merits of both a novel Weighted Aggregated Sum-Product Assessment method with Fuzzy values (WASPAS-F) and fuzzy Analytical Hierarchy Process (AHP).

\section{Methodology}

The high value of a problem-solving process is that it helps to align human's thinking and action around a common approach for winning team problem solving to the following nine steps:

1. Selecting the problem;

2. Exploring the problem and gathering data;

3. Establishing success attributes;

4. Developing a clear problem statement;

5. Generating alternatives; 
6. Evaluating alternatives;

7. Selecting a preferred solution;

8. Developing a plan for action;

9. Testing and modifying the solution.

There is no evidence in the literature of publications evaluating the shopping centre construction sites were applied in Lithuania. This is the most powerful motivation to consider the site selection problem. Flowchart of proposed problem solving process is shown in Fig. 1. The first part of methodology, i.e. the fuzzy AHP was used to calculate attributes weights. In the second part, the WASPAS-F method was developed and used to rank and select the alternatives. First

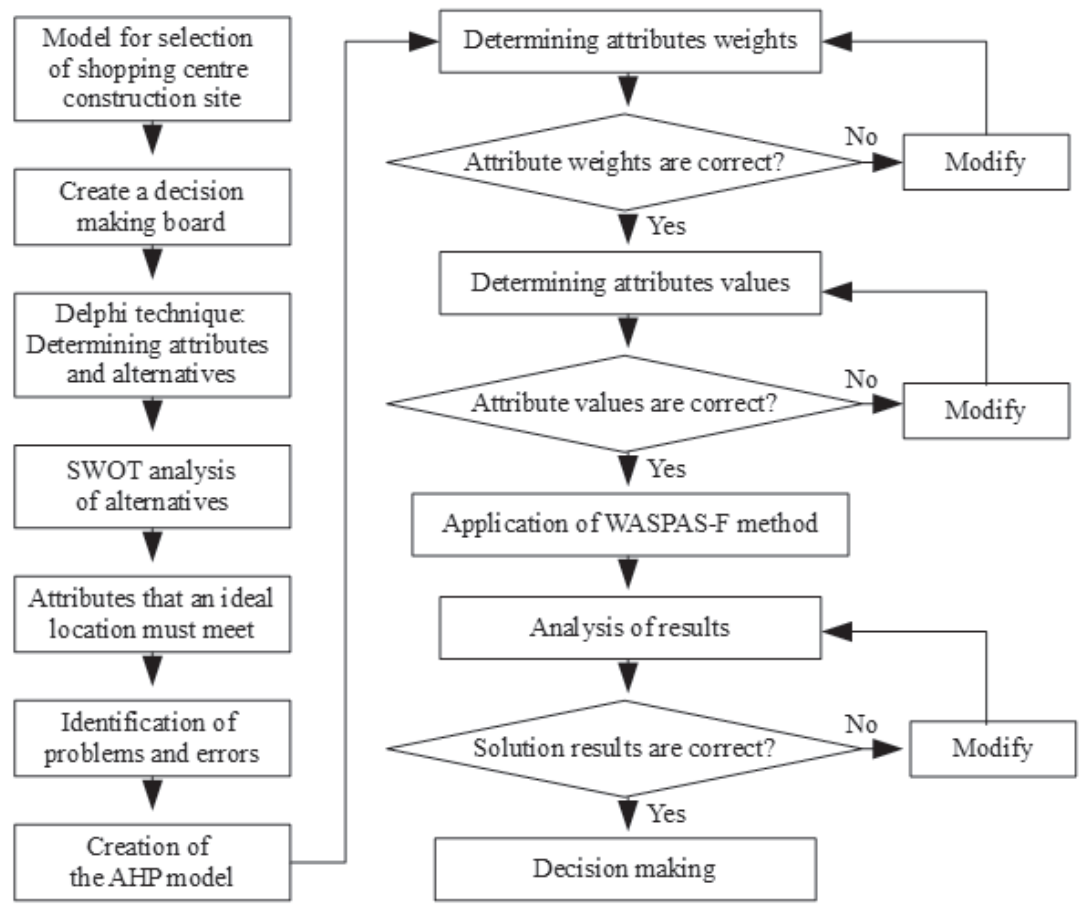

Figure 1: Flowchart of the proposed problem solving process

of all expert group was formed. The creditability of a group of experts depends on the expertise of the people who are involved and how they can give full play to their professional expertise and make wise and fair decisions. The group of experts was formed based on three main problem solving skills:

1. Communications patience (techniques that help members share information and perspectives by working hard to understand one another and working hard to be understood, members with controversial or divergent views are not ignored or blocked);

2. Synergy creation (techniques that equip members to expand their thinking by generating many ideas, building on those ideas, and evaluating ideas to create synergistic solutions);

3. Disciplined use of a problem solving process (members become disciplined in using a systematic process for analysing data, creating options, and evaluating and selecting preferred solutions). 
In the absence of good data, members waste time in pointless debates over opinions, and the problem with opinions is that we all have different ones. The members were asked to generate as many ideas or options as they can without censorship or judgment. Ideas were evaluated considering all factors consequences and sequels of all the probable consequences of a particular scenario in the short term, the medium term, and the longer term. The members were asked to identify important criteria for assessing the feasibility of several ideas.

\subsection{Preliminairies}

A fuzzy set is a class of objects with a continuum of membership grades. Such set is characterized by a membership function which assigns to each object a grade of membership ranging between zero and one [9]. A fuzzy set $A$ defined in space $X$ is a set of pairs:

$$
A=\left\{\left(x, \mu_{A}(x)\right), x \in X\right\},
$$

where the fuzzy set $A$ is characterized by its membership function $\mu_{A}: X \rightarrow[0 ; 1]$, which associates with each element $x \in X$, a real number $\mu_{A}(x) \in[0 ; 1]$. The value $\mu_{A}(x)$ at $x$ represents the grade of membership of $x$ in $A$ and is interpreted as the membership degree to which $x$ belongs to $A$. So the closer the value $\mu_{A}(x)$ is to 1 , the more $x$ belongs to $A$.

A crisp or ordinary subset $A$ of $X$ can also be viewed as a fuzzy set in $X$ with membership function as its characteristic function, i.e.

$$
\mu_{A}(x)= \begin{cases}1 & x \in A \\ 0 & x \notin A .\end{cases}
$$

The set $X$ is called a universe of discourse and can be written $\subseteq X$. Sometimes a fuzzy set $A$ in $X$ is denoted by list the ordered pairs $\left(x, \mu_{A}(x)\right)$, where the elements with zero degree are usually not listed. Thus a fuzzy set $A$ in $X$ can be represented as $A=\left\{\left(x, \mu_{A}(x)\right)\right\}$, where $x \in X$ and $\mu_{A}: X \rightarrow[0 ; 1]$.

When the universe of discourse is discrete and finite with cardinality $n$, that is $X=\left\{x_{1}, x_{2}, \ldots, x_{n}\right\}$, the fuzzy set $A$ can be represented as

$$
A=\sum_{i=1}^{n} \frac{\mu_{A}\left(x_{i}\right)}{x_{i}}=\frac{\mu_{A}\left(x_{1}\right)}{x_{1}}+\frac{\mu_{A}\left(x_{2}\right)}{x_{2}}+\ldots+\frac{\mu_{A}\left(x_{n}\right)}{x_{n}},
$$

when the universe of discourse $X$ is an interval of real numbers, the fuzzy set $A$ can be expressed as

$$
A=\int_{X} \frac{\mu_{A}(x)}{x} .
$$

A fuzzy number $A$ is defined to be a fuzzy triangular number, with $\alpha$-lower, $\beta$ - modal, and $\gamma$-upper values, if its membership function $\mu_{A}: X \rightarrow[0 ; 1]$ is fully described as follows:

$$
\mu_{A}(x)= \begin{cases}\frac{x-\alpha}{\beta-\alpha} & \text { if } x \in[\alpha, \beta], \\ \frac{x-\alpha}{\beta-\gamma} & \text { if } x \in[\beta, \gamma], \quad \alpha \leqslant \beta \leqslant \gamma . \\ 0 & \text { otherwise. }\end{cases}
$$

In order to obtain a crisp output, a defuzzification process is needed to be applied. Defuzzification is the process of producing a quantifiable result in fuzzy logic, given fuzzy sets and corresponding membership degrees. The output of the defuzzification process is a single number. Various types of membership functions are used. The most commonly used membership 
functions are the following [24]: triangular, trapezoid, linear, sigmoidal, $\pi$-type, and Gaussian.

A fuzzy number is generally a subjective data given by one expert or several (after collective agreement). The most typical fuzzy set membership function is triangular membership function (Fig. 2).

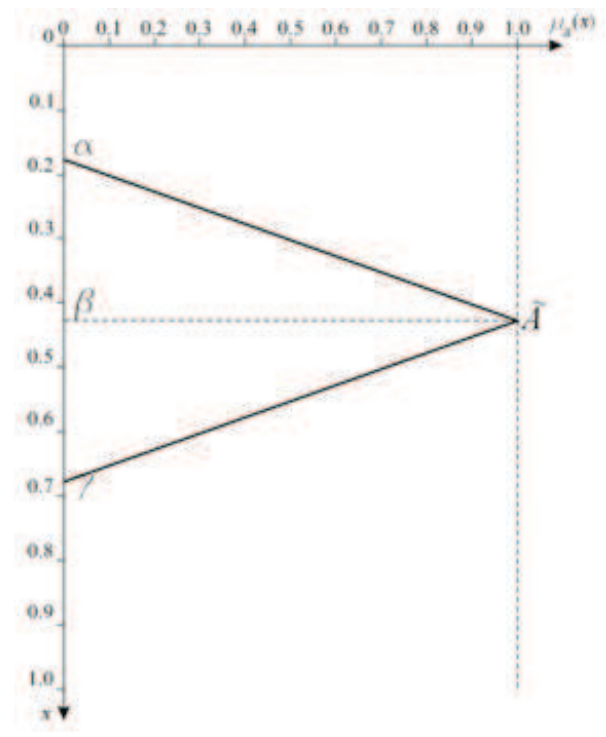

Figure 2: Triangular membership function

Van Laarhoven and Pedrycz [25] introduced the basic operations of fuzzy triangular numbers $\tilde{x}_{1}$ and $\tilde{x}_{2}$ (Table 1 ). In the Table $1 \alpha$ is a lower value of fuzzy number, $\beta$ - modal value of fuzzy number, $\gamma$-upper value of fuzzy number.

Values of weight $0<\tilde{w}_{j}<1, \sum_{j=1}^{n} \tilde{w}_{j}=1$ are usually determined by experts. There are various approaches for assessing weights. Decision makers data which cannot be exactly described by means of numerical values, commonly describe the different ways they measure things numerically in terms of scales of measurement, which come in four flavours: nominal, ordinal, interval, or ratio scales. Likert items were first introduced in 1932 [26]. Likert scales can indeed be analysed effectively as interval or fuzzy scales [27] in which categories are labelled with numerical values.

\subsection{Fuzzy AHP}

The earliest work in fuzzy AHP appeared in van Laarhoven and Pedrycz [25], which compared fuzzy ratios described by triangular membership functions. Chang [28] introduced a new approach for handling fuzzy AHP, with the use of triangular fuzzy numbers for pairwise comparison scale of fuzzy AHP, and the use of the extent analysis method for the synthetic extent values of the pairwise comparisons. This study concentrates on a fuzzy AHP approach introduced by Chang [28], in which triangular fuzzy numbers are preferred for pairwise comparison scale. This questionnaire sought the satisfaction level of the experts concerning the candidate alternatives using a Likert-type five-point scale. The linguistic variables matching TFNs are provided in Fig.3.

Fuzzy group weight is determined as follows:

After obtaining the attributes weights from AHP the synthesising of ratio judgements is done. $\tilde{W}=\left[\tilde{w}_{1}, \tilde{w}_{n}\right]=\left[\tilde{w}_{j}\right]$ fuzzy group weights for $n$ attributes are determined as follows $\left(\tilde{w}_{j}\right.$ is fuzzy 
Table 1: Basic operations on fuzzy triangular numbers

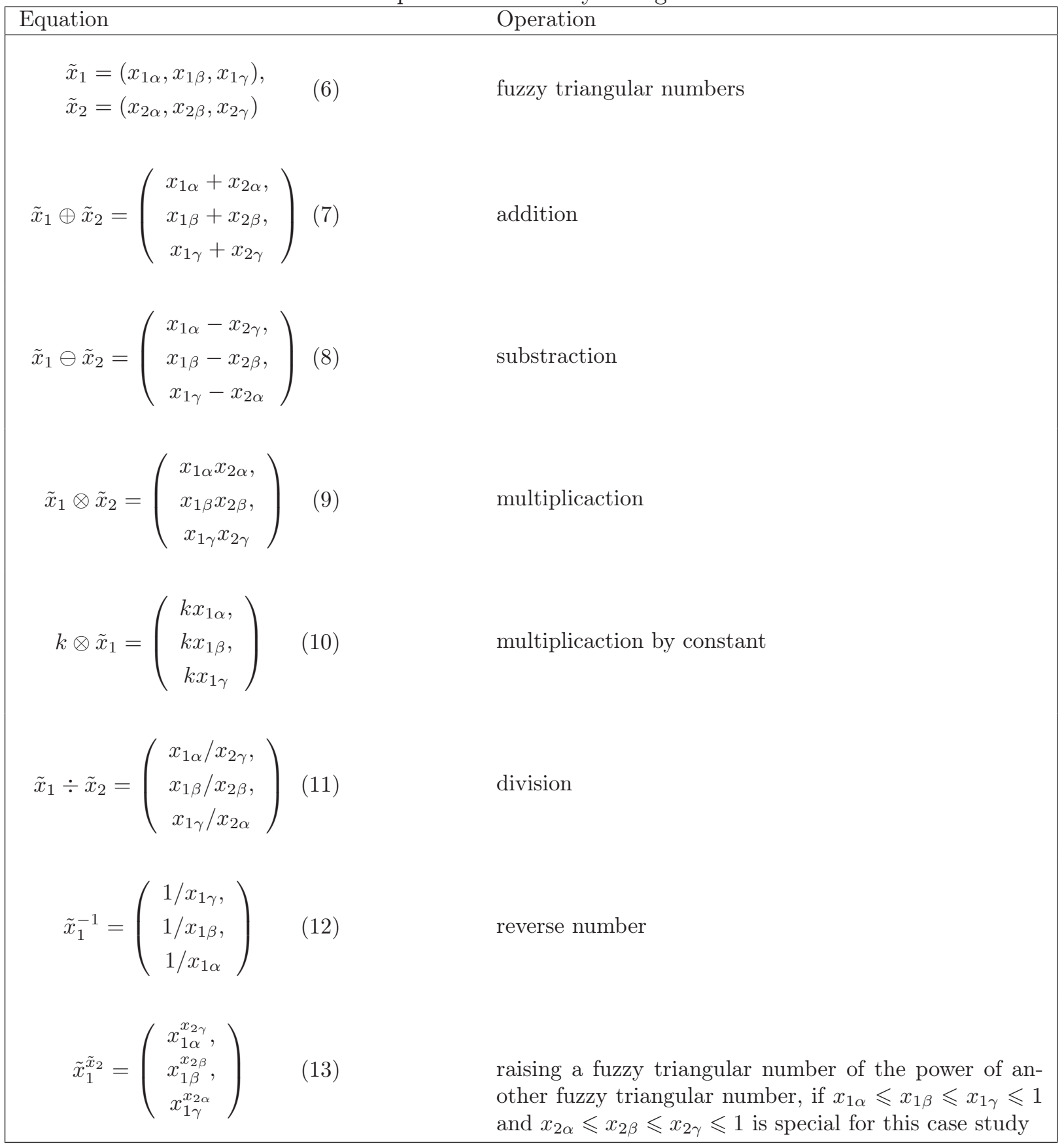

triangular number):

$$
\tilde{x}_{j}=\left(x_{j \alpha}, x_{j \beta}, x_{j \gamma}\right)
$$

where $y_{j k}$ is $j$ attribute weight determined by $k$ expert, $p$ is number of experts, $w_{j \alpha}=\min _{k} y_{j k}, j=$ $\overline{1, n}, k=\overline{1, p}$ is minimum possible value, $w_{j \beta}=\left(\prod_{k=1}^{p} y_{j k}\right)^{1 / p}, j=\overline{1, n}$ is the most possible value and $w_{j \gamma}=\max _{k} y_{j k}, j=\overline{1, n}, k=\overline{1, p}$ is maximum possible value of $j$ attribute weight. 


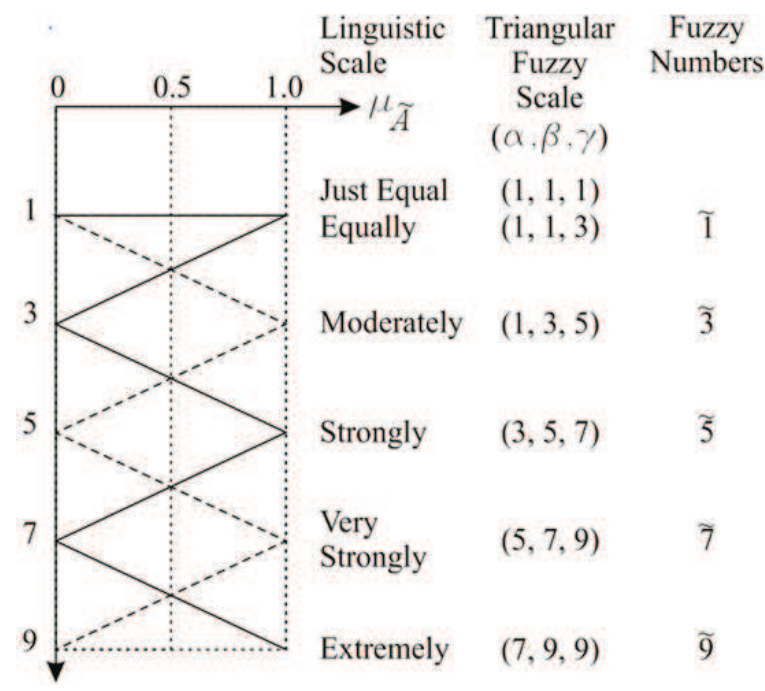

Figure 3: Linguistic variables for the importance weight of each attribute.

\subsection{A novel fuzzy multi-attribute performance measurement model: Weighted Aggregated Sum-Product Assessment method with Fuzzy val- ues (WASPAS-F)}

This subsection extends WASPAS to the fuzzy environment. The merit of using a fuzzy approach is to assign the relative importance of attributes using fuzzy numbers instead of precise numbers. MADM method, namely WASPAS, was introduced in 2012 by Zavadskas et al. [29]. Later, modification of the method WASPAS-IFIV was introduced [30]. There are a number of applications of WASPAS method, including site selection for wind turbine [31], deciding shopping mall locating [32] or assessing sites for implementation of solar projects [33]. Also the method was successfully applied for evaluating alternative technological or design solutions in construction [34] - [37], manufacturing [38], business issues [39] or even for performance analysis and ranking of scholarly journals $[40]$.

The WASPAS method consists of two aggregated parts:

1. The Weighted Sum Model (WSM);

2. The Weighted Product Model (WPM).

The WSM method is simple, easy to use and understood. It determines overall score of an alternative as a weighted sum of the attribute values. It is the best known and most widely used method [41]. The WPM is developed in order to avoid alternatives with poor attribute values. It determines score of each alternative as a product of the scale rating of each attribute to a power equal to the importance weight of the attribute [42].

Based on the briefly summarized fuzzy theory above, WASPAS-F steps can be outlined as follows:

Step 1. Forming of fuzzy decision-making matrix (FDMM). The performance values $\tilde{x}_{i j}$ and the attributes weights $\tilde{w}_{j}$ are entries of a DMM. Choose the linguistic ratings.

The system of attributes as well as the values and initial weights of attributes are determined by experts. The discrete optimization problem is represented by the preferences for $m$ reasonable alternatives (rows) rated on $n$ attributes (columns): 


$$
\tilde{X}=\left[\begin{array}{ccccc}
\tilde{x}_{11} & \ldots & \tilde{x}_{1 j} & \ldots & \tilde{x}_{1 n} \\
\vdots & \ddots & \vdots & \ddots & \vdots \\
\tilde{x}_{i 1} & \ldots & \tilde{x}_{i j} & \ldots & \tilde{x}_{i n} \\
\vdots & \ddots & \vdots & \ddots & \vdots \\
\tilde{x}_{m 1} & \ldots & \tilde{x}_{m j} & \ldots & \tilde{x}_{m n}
\end{array}\right] ; i=\overline{1, m}, j=\overline{1, n}
$$

where $\tilde{x}_{i j}$ - fuzzy value representing the performance value of the $i$ alternative in terms of the $j$ attribute. A tilde ${ }^{\sim}$ is placed above a symbol if the symbol represents a fuzzy set.

Then the determination of the priorities of alternatives is carried out in several steps.

Step 2. The initial values of all the attributes $\tilde{x}_{i j}$ are normalised - defining values $\tilde{\bar{x}}_{i j}$ of normalised decision-making matrix $\tilde{\bar{X}}=\left[\tilde{\bar{x}}_{i j}\right]_{m \times n}$.

$$
\tilde{\bar{x}}_{i j}=\left\{\begin{array}{l}
\frac{\tilde{x}_{i j}}{\max _{i} \tilde{x}_{i j}} \quad \text { if } \max _{i} \tilde{x}_{i j} \text { is preferable, } \\
\frac{\min _{i} \tilde{x}_{i j}}{\tilde{x}_{i j}} \quad \text { if } \min _{i} \tilde{x}_{i j} \text { is preferable; }
\end{array} i=\overline{1, m}, j=\overline{1, n} .\right.
$$

Step 3a. Calculate the weighted normalised fuzzy decision matrix $\tilde{\hat{X}}_{q}$ for WSM:

$$
\tilde{\hat{X}}_{q}=\left[\begin{array}{ccccc}
\tilde{\hat{x}}_{11} & \ldots & \tilde{\hat{x}}_{1 j} & \ldots & \tilde{\hat{x}}_{1 n} \\
\vdots & \ddots & \vdots & \ddots & \vdots \\
\tilde{\hat{x}}_{i 1} & \ldots & \tilde{\hat{x}}_{i j} & \ldots & \tilde{\hat{x}}_{i n} \\
\vdots & \ddots & \vdots & \ddots & \vdots \\
\tilde{\hat{x}}_{m 1} & \ldots & \tilde{\hat{x}}_{m j} & \ldots & \tilde{\hat{x}}_{m n}
\end{array}\right] ; \tilde{\hat{x}}_{i j}=\tilde{\bar{x}}_{i j} \tilde{w}_{j}, i=\overline{1, m}, j=\overline{1, n} .
$$

Step 3b. Calculate the weighted normalised fuzzy decision matrix $\tilde{\hat{X}}_{p}$ for WPM:

$$
\tilde{\hat{X}}_{p}=\left[\begin{array}{ccccc}
\tilde{\overline{\bar{x}}}_{11} & \ldots & \tilde{\overline{\bar{x}}}_{1 j} & \ldots & \tilde{\overline{\bar{x}}}_{1 n} \\
\vdots & \ddots & \vdots & \ddots & \vdots \\
\tilde{\overline{\bar{x}}}_{i 1} & \ldots & \tilde{\overline{\bar{x}}}_{i j} & \ldots & \tilde{\overline{\bar{x}}}_{i n} \\
\vdots & \ddots & \vdots & \ddots & \vdots \\
\tilde{\overline{\bar{x}}}_{m 1} & \ldots & \tilde{\overline{\bar{x}}}_{m j} & \ldots & \tilde{\overline{\bar{x}}}_{m n}
\end{array}\right] ; \tilde{\overline{\bar{x}}}_{i j}=\tilde{\tilde{x}}_{i j}, i=\overline{1, m}, j=\overline{1, n} .
$$

Step 4. Calculate values of the optimality function:

a) according to the WSM for each alternative:

$$
\tilde{Q}_{i}=\sum_{j=1}^{n} \tilde{\hat{x}}_{i j}, i=\overline{1, m},
$$

b) according to the WPM for each alternative:

$$
\tilde{P}_{i}=\prod_{j=1}^{n} \tilde{\overline{\bar{x}}}_{i j}, i=\overline{1, m}
$$


The result of fuzzy performance measurement for each alternative are fuzzy numbers $\tilde{Q}_{i}$ and $\tilde{P}_{i}$. The centre-of-area is the most practical and simple to apply for defuzzification:

$$
\begin{aligned}
Q_{i} & =\frac{1}{3}\left(Q_{i \alpha}+Q_{i \beta}+Q_{i \gamma}\right) . \\
P_{i} & =\frac{1}{3}\left(P_{i \alpha}+P_{i \beta}+P_{i \gamma}\right) .
\end{aligned}
$$

Step 5. The integrated utility function value of the WASPAS-F method for an alternative could be determined as follows:

$$
K_{i}=\lambda \sum_{j=1}^{m} Q_{i}+(1-\lambda) \sum_{j=1}^{m} P_{i}, \lambda=0, \ldots, 1,0 \leqslant K_{i} \leqslant 1 .
$$

$\lambda$ is determined based on the assumption that total of all alternatives WSM scores must be equal to the total of WPM scores:

$$
\lambda=\frac{\sum_{i=1}^{m} P_{i}}{\sum_{i=1}^{m} Q_{i}+\sum_{i=1}^{m} P_{i}} .
$$

Step 6. Rank preference order. Choose an alternative with maximal $K_{i}$ value.

\section{Construction site for shopping centre site selection in Vilnius}

In this case study, an investor company conducted a feasibility study to establish strategies to locate an appropriate shopping centre in strategic demand areas of Vilnius. The identification of feasible sites and the selection of the one will optimize the company's performance strategically. The problem was solved according to the presented above methodology. The MAPM model has been designed by considering the interests and objectives of all stakeholders, customers, local community, employees and suppliers. First of all, expert's team determined the potential critical errors of construction site location selection (Fig. 4). Then, based on expert team questionnaire they determined the main problems of construction site selection (Fig. 5).

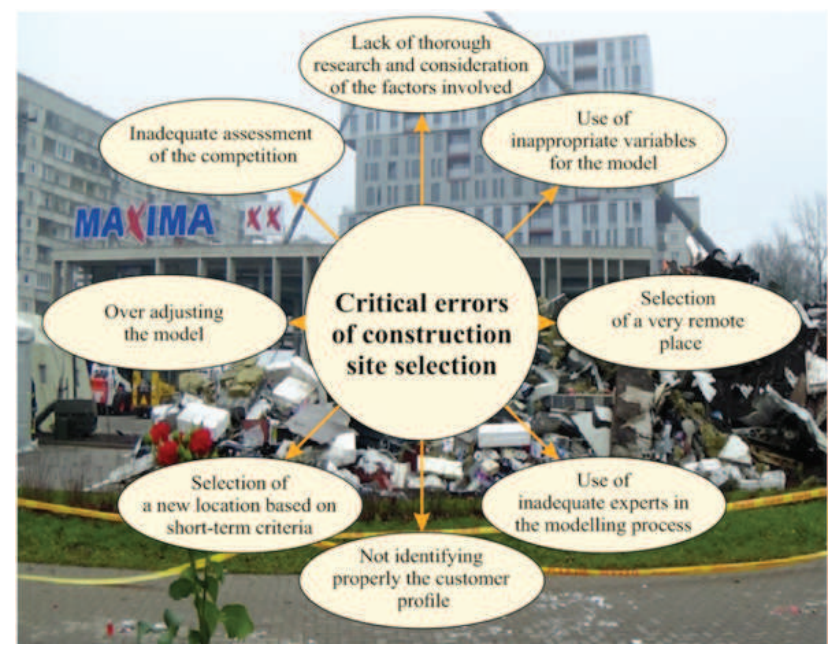

Figure 4: Critical errors of construction site selection. 


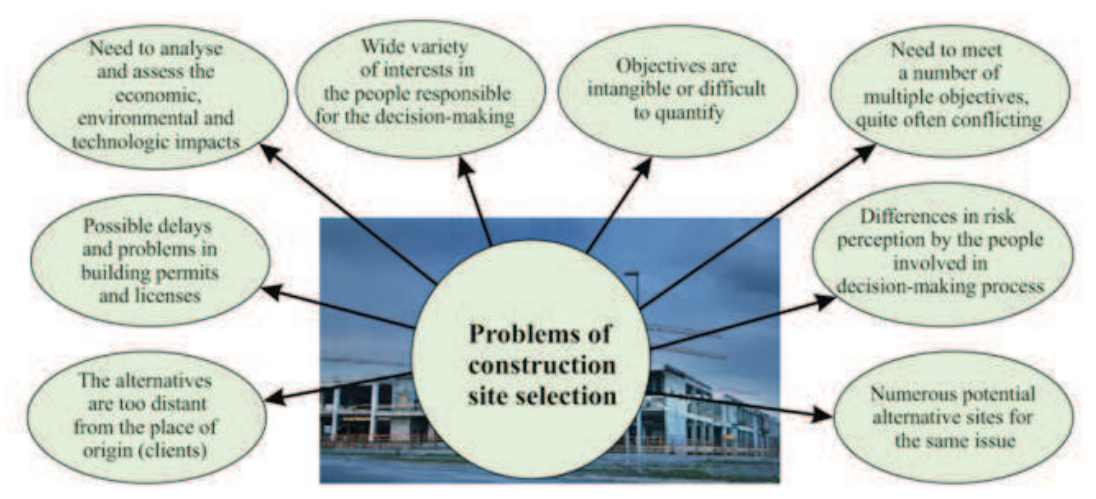

Figure 5: Problems of construction site selection.

An interview to evaluate the most suitable location alternatives was conducted with seven experts, including stakeholders, business development managers, real estate consultants and academicians. The next step was collection of the information associated to all of the alternative construction sites identified and a description of the most important attributes. The Strengths, Weaknesses, Opportunities, and Threats analysis was performed. Finally, four location alternatives, which are denoted as $A_{1}, A_{2}, A_{3}$ and $A_{4}$ are selected as feasible alternatives. $A_{1}$ alternative is at the intersection of important roads between the airport and the railway station and the central bus station. $A_{2}$ is one of the developing dwelling districts. $A_{3}$ is the most populated residential district. $A_{4}$ is one of the nearby the centre point of the Vilnius.

Later, the attributes were compared each other using AHP. A Likert-type ten-point scale (Fig. 3) was used.

In the next step the questionnaire was about experts' satisfaction level toward construction site selection. This questionnaire adopts a Likert-type ten-point scale (Fig. 6). It has ten different levels - from "very bad" $\left(\tilde{P}_{1}\right)$ to "excellent" $\left(\tilde{P}_{10}\right)$ - on a fuzzy ten-level scale. For example, expert might think the satisfaction the linguistic score of "fair" $\left(\tilde{P}_{5}\right)$, that score would or correspond to a TFN of $(0.4,0.5,0.6)$ respectively. The pairwise comparison matrix set by TFNs that matches linguistic statements of data is shown in Table 2. Each of experts determined attributes weights. Integrated results of established weights are shown in Table 3. The priority weight vector describes the importance degree of the attributes in decision matrix. After getting the importance degree of attributes, WASPAS-F method was employed to evaluate alternative locations. In this phase of the study, WASPAS-F starts establishing fuzzy evaluations of the alternative locations $\left(A_{1}, A_{2}, A_{3}\right.$ and $\left.A_{4}\right)$ with respect to the attributes by using TFNs. This is an initial decision making matrix for ranking alternatives and indicates the performance ratings of the alternatives according to the attributes. The alternatives according to linguistic scales and their corresponding fuzzy numbers $\{(1,1,1)$ - very poor, $(2,3,4)$ - poor, $(4,5,6)$ - fair, $(6,7,8)$ good, $(8,9,10)$ - very good $\}$ are compared by experts. Table 4 shows comparison of alternatives according to attributes. The normalised decision matrix is obtained by using Eq. (16) (Table 5). The weighted normalised fuzzy decision matrix for WSM is obtained by using Eq. (17) (Table 6) and one for WPM is obtained by using Eq. (18) (Table 7). Values of the optimality function values for WSM and WPM are calculated by using Eq. (19) and Eq. (20) respectively. The integrated utility function value of the WASPAS-F method for an alternative was determined by using Eq. (24), as presented in Table 8.

As can be seen from Table $8, A_{3}$ is the best alternative in the WSM, WPM and WASPAS method. $A_{4}$ alternative is the worst among considered alternatives. Decision maker should choose and implement the $A_{3}$ alternative. 
Table 2: Pairwise comparisons of site selection attributes for shopping centre via TFN (The first Expert).

\begin{tabular}{|c|c|c|c|c|c|c|c|c|c|c|}
\hline & & $x_{1}$ & $x_{2}$ & $x_{3}$ & $x_{4}$ & $x_{5}$ & $x_{6}$ & $x_{7}$ & $x_{8}$ & $w$ \\
\hline $\begin{array}{l}\text { Construction } \\
\text { costs }\end{array}$ & $x_{1}$ & $1,1,1$ & $0.20,0.33,1$ & $1,1,3$ & $1,3,5$ & $5,7,9$ & $3,5,7$ & $3,5,7$ & $3,5,7$ & 0.21 \\
\hline Economical & $x_{2}$ & $1,3,5$ & $1,1,1$ & $1,1,3$ & $1,3,5$ & $3,5,7$ & $1,3,5$ & $3,5,7$ & $3,5,7$ & 0.21 \\
\hline Road & & & & & & & & & & \\
\hline accesses & $x_{3}$ & $0.33,1,1$ & $0.33,1,1$ & $1,1,1$ & $0.20,0.33,1$ & $1,3,5$ & $3,5,7$ & $1,3,5$ & $1,3,5$ & 0.17 \\
\hline Competition & $x_{4}$ & $0.20,0.33,1$ & $0.20,0.33,1$ & $1,3,5$ & $1,1,1$ & $1,3,5$ & $1,3,5$ & $1,3,5$ & $1,3,5$ & 0.17 \\
\hline $\begin{array}{c}\text { Population } \\
\text { characteristics }\end{array}$ & $x_{5}$ & $0.11,0.14,0.20$ & $0.14,0.20,0.33$ & $0.20,0.33,1$ & $0.20,0.33,1$ & $1,1,1$ & $3,5,7$ & $1,3,5$ & $1,1,3$ & 0.12 \\
\hline Environmental & & & & & & & & & & \\
\hline impacts & $x_{6}$ & $0.14,0.20,0.33$ & $0.20,0.33,1$ & $0.14,0.20,0.33$ & $0.20,0.33,1$ & $0.14,0.20,0.33$ & $1,1,1$ & $1,3,5$ & $1,1,3$ & 0.07 \\
\hline Risks & $x_{7}$ & $0.14,0.20,0.33$ & $0.14,0.20,0.33$ & $0.20,0.33,1$ & $0.20,0.33,1$ & $0.20,0.33,1$ & $0.20,0.33,1$ & $1,1,1$ & $1,1,3$ & 0.04 \\
\hline Attractiveness & $x_{8}$ & $0.14,0.20,0.33$ & $0.14,0.20,0.33$ & $0.20,0.33,1$ & $0.20,0.33,1$ & $0.33,1,1$ & $0.33,1,1$ & $0.33,1,1$ & $1,1,1$ & 0.01 \\
\hline
\end{tabular}

Table 3: Fuzzy weights of attributes

\begin{tabular}{|l|l|l|l|l|l|l|l|l|l|l|}
\hline & \multicolumn{7}{|c|}{ Experts } & \multicolumn{3}{|c|}{$\tilde{W}$} \\
\hline & $E_{1}$ & $E_{2}$ & $E_{3}$ & $E_{4}$ & $E_{5}$ & $E_{6}$ & $E_{7}$ & $w_{j \alpha}$ & $w_{j \beta}$ & $w_{j \gamma}$ \\
\hline$x_{1}$ & 0.21 & 0.33 & 0.29 & 0.31 & 0.23 & 0.35 & 0.27 & 0.21 & 0.28 & 0.35 \\
\hline$x_{2}$ & 0.21 & 0.23 & 0.18 & 0.21 & 0.23 & 0.17 & 0.16 & 0.16 & 0.20 & 0.23 \\
\hline$x_{3}$ & 0.17 & 0.16 & 0.14 & 0.17 & 0.14 & 0.17 & 0.16 & 0.14 & 0.16 & 0.17 \\
\hline$x_{4}$ & 0.17 & 0.11 & 0.09 & 0.10 & 0.14 & 0.12 & 0.12 & 0.09 & 0.12 & 0.17 \\
\hline$x_{5}$ & 0.12 & 0.07 & 0.09 & 0.07 & 0.08 & 0.08 & 0.09 & 0.07 & 0.08 & 0.12 \\
\hline$x_{6}$ & 0.07 & 0.05 & 0.07 & 0.05 & 0.08 & 0.05 & 0.09 & 0.05 & 0.06 & 0.09 \\
\hline$x_{7}$ & 0.04 & 0.03 & 0.07 & 0.05 & 0.05 & 0.04 & 0.05 & 0.03 & 0.05 & 0.07 \\
\hline$x_{8}$ & 0.01 & 0.02 & 0.06 & 0.02 & 0.05 & 0.02 & 0.05 & 0.01 & 0.03 & 0.06 \\
\hline
\end{tabular}

Table 4: The initial fuzzy decision making matrix for construction site selection

\begin{tabular}{|l|l|l|l|l|l|l|l|l|l|l|l|l|l|l|l|r|r|}
\hline & \multicolumn{4}{|c|}{$W$} & \multicolumn{3}{|c|}{$A_{1}$} & \multicolumn{3}{|c|}{$A_{2}$} & \multicolumn{3}{|c|}{$A_{3}$} & \multicolumn{3}{|c|}{$A_{4}$} & max \\
\cline { 2 - 8 } & $\alpha$ & $\gamma$ & $\alpha$ & $\beta$ & $\gamma$ & $\alpha$ & $\beta$ & $\gamma$ & $\alpha$ & $\beta$ & $\gamma$ & $\alpha$ & $\beta$ & $\gamma$ & \\
\hline$\tilde{x}_{1}$ & 0.21 & 0.28 & 0.35 & 0.5 & 0.6 & 0.7 & 0.6 & 0.7 & 0.8 & 0.6 & 0.7 & 0.8 & 0.6 & 0.7 & 0.8 & 0.8 \\
\hline$\tilde{x}_{2}$ & 0.16 & 0.20 & 0.23 & 0.6 & 0.7 & 0.8 & 0.6 & 0.7 & 0.8 & 0.8 & 0.9 & 1.0 & 0.5 & 0.6 & 0.7 & 1 \\
\hline$\tilde{x}_{3}$ & 0.14 & 0.16 & 0.17 & 0.8 & 0.9 & 1.0 & 0.5 & 0.6 & 0.7 & 0.6 & 0.7 & 0.8 & 0.6 & 0.7 & 0.8 & 1 \\
\hline$\tilde{x}_{4}$ & 0.09 & 0.12 & 0.17 & 0.5 & 0.6 & 0.7 & 0.6 & 0.7 & 0.8 & 0.5 & 0.6 & 0.7 & 0.4 & 0.5 & 0.6 & 0.8 \\
\hline$\tilde{x}_{5}$ & 0.07 & 0.08 & 0.12 & 0.8 & 0.9 & 1.0 & 0.7 & 0.8 & 0.9 & 0.6 & 0.7 & 0.8 & 0.5 & 0.6 & 0.7 & 1 \\
\hline$\tilde{x}_{6}$ & 0.05 & 0.06 & 0.09 & 0.5 & 0.6 & 0.7 & 0.8 & 0.9 & 1.0 & 0.6 & 0.7 & 0.8 & 0.8 & 0.9 & 1.0 & 1 \\
\hline$\tilde{x}_{7}$ & 0.03 & 0.05 & 0.07 & 0.4 & 0.5 & 0.6 & 0.5 & 0.6 & 0.7 & 0.8 & 0.9 & 1.0 & 0.7 & 0.8 & 0.9 & 1 \\
\hline$\tilde{x}_{8}$ & 0.01 & 0.03 & 0.06 & 0.5 & 0.6 & 0.7 & 0.4 & 0.5 & 0.6 & 0.4 & 0.5 & 0.6 & 0.5 & 0.6 & 0.7 & 0.7 \\
\hline
\end{tabular}

Table 5: The normalised fuzzy decision making matrix

\begin{tabular}{|c|c|c|c|c|c|c|c|c|c|c|c|c|c|c|c|}
\hline & \multicolumn{3}{|c|}{$\tilde{W}$} & \multicolumn{3}{|c|}{$A_{1}$} & \multicolumn{3}{|c|}{$A_{2}$} & \multicolumn{3}{|c|}{$A_{3}$} & \multicolumn{3}{|c|}{$A_{4}$} \\
\hline & $\alpha$ & $\beta$ & $\gamma$ & $\alpha$ & $\beta$ & $\gamma$ & $\alpha$ & $\beta$ & $\gamma$ & $\alpha$ & $\beta$ & $\gamma$ & $\alpha$ & $\beta$ & $\gamma$ \\
\hline$\tilde{\bar{x}}_{1}$ & 0.21 & 0.28 & 0.35 & 0.63 & 0.75 & 0.88 & 0.75 & 0.88 & 1.00 & 0.75 & 0.88 & 1.00 & 0.75 & 0.88 & 1.00 \\
\hline$\tilde{\bar{x}}_{2}$ & 0.16 & 0.20 & 0.23 & 0.60 & 0.70 & 0.80 & 0.60 & 0.70 & 0.80 & 0.80 & 0.90 & 1.00 & 0.50 & 0.60 & 0.70 \\
\hline$\overline{\bar{x}}_{3}$ & 0.14 & 0.16 & 0.17 & 0.80 & 0.90 & 1.00 & 0.50 & 0.60 & 0.70 & 0.60 & 0.70 & 0.80 & 0.60 & 0.70 & 0.80 \\
\hline$\overline{\bar{x}}_{4}$ & 0.09 & 0.12 & 0.17 & 0.63 & 0.75 & 0.88 & 0.75 & 0.88 & 1.00 & 0.63 & 0.75 & 0.88 & 0.50 & 0.63 & 0.75 \\
\hline$\overline{\tilde{x}}_{5}$ & 0.07 & 0.08 & 0.12 & 0.80 & 0.90 & 1.00 & 0.70 & 0.80 & 0.90 & 0.60 & 0.70 & 0.80 & 0.50 & 0.60 & 0.70 \\
\hline$\tilde{\bar{x}}_{6}$ & 0.05 & 0.06 & 0.09 & 0.50 & 0.60 & 0.70 & 0.80 & 0.90 & 1.00 & 0.60 & 0.70 & 0.80 & 0.80 & 0.90 & 1.00 \\
\hline$\overline{\bar{x}}_{7}$ & 0.03 & 0.05 & 0.07 & 0.40 & 0.50 & 0.60 & 0.50 & 0.60 & 0.70 & 0.80 & 0.90 & 1.00 & 0.70 & 0.80 & 0.90 \\
\hline$\tilde{\bar{x}}_{8}$ & 0.01 & 0.03 & 0.06 & 0.71 & 0.86 & 1.00 & 0.57 & 0.71 & 0.86 & 0.57 & 0.71 & 0.86 & 0.71 & 0.86 & 1.00 \\
\hline
\end{tabular}


Table 6: The weighted normalised matrix for WSM

\begin{tabular}{|c|c|c|c|c|c|c|c|c|c|c|c|c|}
\hline & \multicolumn{3}{|c|}{$A_{1}$} & \multicolumn{3}{|c|}{$A_{2}$} & \multicolumn{3}{|c|}{$A_{3}$} & \multicolumn{3}{|c|}{$A_{4}$} \\
\hline & $\alpha$ & $\beta$ & $\gamma$ & $\alpha$ & $\beta$ & $\gamma$ & $\alpha$ & $\beta$ & $\gamma$ & $\alpha$ & $\beta$ & $\gamma$ \\
\hline$\tilde{\hat{x}}_{1}$ & 0.13 & 0.21 & 0.31 & 0.16 & 0.25 & 0.35 & 0.16 & 0.25 & 0.35 & 0.16 & 0.25 & 0.35 \\
\hline$\tilde{\hat{x}}_{2}$ & 0.10 & 0.14 & 0.18 & 0.10 & 0.14 & 0.18 & 0.13 & 0.18 & 0.23 & 0.08 & 0.12 & 0.16 \\
\hline$\tilde{\hat{x}}_{3}$ & 0.11 & 0.14 & 0.17 & 0.07 & 0.10 & 0.12 & 0.08 & 0.11 & 0.14 & 0.08 & 0.11 & 0.14 \\
\hline$\tilde{\hat{x}}_{4}$ & 0.06 & 0.09 & 0.15 & 0.07 & 0.11 & 0.17 & 0.06 & 0.09 & 0.15 & 0.05 & 0.08 & 0.13 \\
\hline$\tilde{\hat{x}}_{5}$ & 0.06 & 0.07 & 0.12 & 0.05 & 0.06 & 0.11 & 0.04 & 0.06 & 0.10 & 0.04 & 0.05 & 0.08 \\
\hline$\tilde{\hat{x}}_{6}$ & 0.03 & 0.04 & 0.06 & 0.04 & 0.05 & 0.09 & 0.03 & 0.04 & 0.07 & 0.04 & 0.05 & 0.09 \\
\hline$\hat{\hat{x}}_{7}$ & 0.01 & 0.03 & 0.04 & 0.02 & 0.03 & 0.05 & 0.02 & 0.05 & 0.07 & 0.02 & 0.04 & 0.06 \\
\hline$\tilde{\hat{x}}_{8}$ & 0.01 & 0.03 & 0.06 & 0.01 & 0.02 & 0.05 & 0.01 & 0.02 & 0.05 & 0.01 & 0.03 & 0.06 \\
\hline$Q$ & & & 0.78 & & & 0.79 & & & 0.82 & & & 0.75 \\
\hline$\sum Q_{i}$ & & & & & & & & & & & & 3.15 \\
\hline
\end{tabular}

Table 7: The weighted normalised matrix for WPM

\begin{tabular}{|c|c|c|c|c|c|c|c|c|c|c|c|c|}
\hline & \multicolumn{3}{|c|}{$A_{1}$} & \multicolumn{3}{|c|}{$A_{2}$} & \multicolumn{3}{|c|}{$A_{3}$} & \multicolumn{3}{|c|}{$A_{4}$} \\
\hline & $\alpha$ & $\beta$ & $\gamma$ & $\alpha$ & $\beta$ & $\gamma$ & $\alpha$ & $\beta$ & $\gamma$ & $\alpha$ & $\beta$ & $\gamma$ \\
\hline$\overline{\overline{\bar{x}}}_{1}$ & 0.85 & 0.92 & 0.97 & 0.90 & 0.96 & 1.00 & 0.90 & 0.96 & 1.00 & 0.90 & 0.96 & 1.00 \\
\hline$\tilde{\overline{\bar{x}}}_{2}$ & 0.89 & 0.93 & 0.96 & 0.89 & 0.93 & 0.96 & 0.95 & 0.98 & 1.00 & 0.85 & 0.90 & 0.94 \\
\hline$\tilde{\overline{\bar{x}}}_{3}$ & 0.96 & 0.98 & 1.00 & 0.89 & 0.92 & 0.95 & 0.92 & 0.94 & 0.97 & 0.92 & 0.94 & 0.97 \\
\hline$\overline{\overline{\bar{x}}}_{4}$ & 0.92 & 0.97 & 0.99 & 0.95 & 0.98 & 1.00 & 0.92 & 0.97 & 0.99 & 0.89 & 0.95 & 0.97 \\
\hline$\tilde{\overline{\bar{x}}}_{5}$ & 0.97 & 0.99 & 1.00 & 0.96 & 0.98 & 0.99 & 0.94 & 0.97 & 0.98 & 0.92 & 0.96 & 0.98 \\
\hline$\overline{\overline{\bar{x}}}_{6}$ & 0.94 & 0.97 & 0.98 & 0.98 & 0.99 & 1.00 & 0.96 & 0.98 & 0.99 & 0.98 & 0.99 & 1.00 \\
\hline$\overline{\bar{x}}_{7}$ & 0.94 & 0.97 & 0.98 & 0.95 & 0.97 & 0.99 & 0.98 & 0.99 & 1.00 & 0.98 & 0.99 & 1.00 \\
\hline$\tilde{\overline{\bar{x}}}_{8}$ & 0.98 & 1.00 & 1.00 & 0.97 & 0.99 & 1.00 & 0.97 & 0.99 & 1.00 & 0.98 & 1.00 & 1.00 \\
\hline$P$ & & & 0.74 & & & 0.75 & & & 0.79 & & & 0.71 \\
\hline$\sum P_{i}$ & & & & & & & & & & & & 2.99 \\
\hline
\end{tabular}

Table 8: Integrated utility function values of the WASPAS-F method

\begin{tabular}{|l|c|c|c|c|}
\hline & $A_{1}$ & $A_{2}$ & $A_{3}$ & $A_{4}$ \\
\hline$Q$ & 0.78 & 0.79 & 0.82 & 0.75 \\
\hline$P$ & 0.74 & 0.75 & 0.79 & 0.71 \\
\hline$\lambda$ & \multicolumn{5}{|c|}{0.49} \\
\hline$K$ & 0.76 & 0.77 & 0.80 & 0.73 \\
\hline Rank & 3 & 2 & 1 & 4 \\
\hline
\end{tabular}




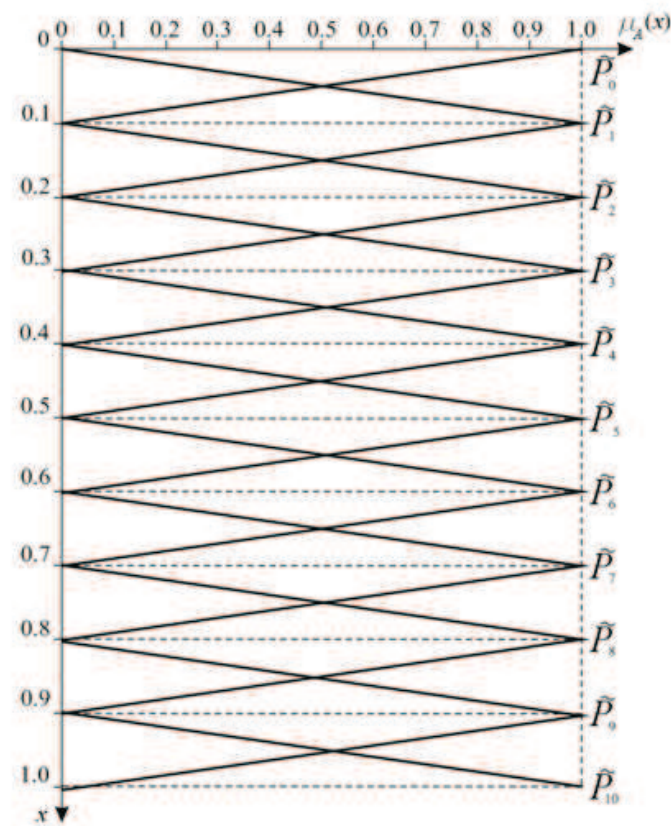

Figure 6: Membership functions of linguistic values for criteria rating (Likert-type ten-point scale).

\section{Conclusions}

Today, increase in population well-being and income causes the need of new construction sites. Selecting the best location for a new construction site in fuzzy environments becomes a difficult task for stakeholders. This paper proposed a combined fuzzy MADM approach based on the fuzzy AHP and WASPAS-F methods for selecting a suitable construction site location. In the proposed method, the fuzzy AHP was used to determine the weights of the attributes, while WASPAS-F was employed to rank the alternative locations. The approach combines the strong sides of the AHP and WASPAS methods. As a result of the study, we find that the proposed method is practical for ranking alternatives with respect to multiple conflicting attributes for the large scale problems.

\section{Bibliography}

[1] Aristotle (1990); Ethica Nicomachea, Oxford University Press, Oxford, Originally published in $350 \mathrm{bc}$, English edition by I. Bywater.

[2] Bernoulli, D. (1954); Specimen theoriae novae de mensurasortis, Commentarii Academiae Scientiarum Imperialis Petropolitanae, Econometrica, 22: 23-36.

[3] Borda, J. C. (1781); Mémoiresur les élections au scrutiny, Comptesrendus de l'Académie des sciences, traduit par Alfred de Graziacomme Mathematical Derivation of an election system, 44: $42-51$.

[4] Von Neumann, J.; Morgenstern, O. (1944); Theory of Games and Economic Behavior, Princeton University Press, Princeton.

[5] Fishburn, P.C. (1970); Utility Theory for Decision Making, Wiley, New York. 
[6] Keeney, R. L.; Raiffa, H. (1976); Decision with Multiple Objectives: Preferences and Value Tradeoffs, John Wiley \& Sons, New York.

[7] Zeleny, M. (1982); Multiple Criteria Decision Making, McGraw-Hill, New York.

[8] Zimmermann, H. J. (2000); An application-oriented view of modelling uncertainty, European Journal of Operational Research, 122: 190-198.

[9] Zadeh, L. A. (1965); Fuzzy sets, Information and Control, 8(3): 338-353.

[10] Zadeh, L. A. (1975); Fuzzy logic and its application to approximate reasoning, Part I, Information Science, 8(3): 199-249

[11] Zadeh, L. A. (1975); Fuzzy logic and its application to approximate reasoning, Part II, Information Science, 8(4): 301-357.

[12] Zadeh, L. A. (1975); Fuzzy logic and its application to approximate reasoning, Part III, Information Science, 9(1): 43-80.

[13] Aydin, N. Y.; Kentel, E.; Duzgun, H. S. (2013); GIS-based site selection methodology for hybrid renewable energy systems: A case study from western Turkey, Energy Conversion and Management, 70: 90-106.

[14] Chatterjee, N.; Bose, G. (2013); A COPRAS-F base multi-criteria group decision making approach for site selection of wind farm, Decision Science Letters, 2(1): 1-10.

[15] Sánchez-Lozano, J. M.; Teruel-Solano, J.; Soto-Elvira, P. L.; García-Cascales, M. S. (2013); Geographical Information Systems (GIS) and Multi-Criteria Decision Making (MCDM) methods for the evaluation of solar farms locations: Case study in south-eastern Spain, Renewable and Sustainable Energy Reviews, 24: 544-556.

[16] Kim, Y.; Chung, E. S.; Jun, S. M.; Kim, S. U. (2013); Prioritizing the best sites for treated wastewater instream use in an urban watershed using fuzzy TOPSIS, Resources, Conservation and Recycling, 73: 23-32.

[17] Liu, H. C.; You, J. X.; Fan, X. J.; Chen, Y. Z. (2014); Site selection in waste management by the VIKOR method using linguistic assessment, Applied Soft Computing, 21: 453-461.

[18] García, J. L.; Alvarado, A.; Blanco, J.; JimĂ ̌̌nez, E.; Maldonado, A. A.; Cort ĂS̆s, G. (2014); Multi-attribute evaluation and selection of sites for agricultural product warehouses based on an analytic hierarchy process, Computers and Electronics in Agriculture, 100: 60-69.

[19] Uyan, M. (2013); GIS-based solar farms site selection using analytic hierarchy process (AHP) in Karapinar region, Konya/Turkey, Renewable and Sustainable Energy Reviews, 28: 11-17.

[20] Devi, K.; Yadav, S. P. (2013); A multicriteria intuitionistic fuzzy group decision making for plant location selection with ELECTRE method, The International Journal of Advanced Manufacturing Technology, 66(9-12): 1219-1229.

[21] Erol, İ.; Sencer, S.; Özmen, A.; Searcy, C. (2014); Fuzzy MCDM framework for locating a nuclear power plant in Turkey, Energy Policy, 67: 186-197.

[22] Wang, J. C.; Chen, T. Y. (2014); A closeness coefficient-based multiple criteria decisionmaking method using interval type-2 fuzzy sets and its application to watershed site selection, Journal of Industrial and Production Engineering, 31(1): 1-16. 
[23] Fetanat, A.; Khorasaninejad, E. (2015); A novel hybrid MCDM approach for offshore wind farm site selection: A case study of Iran, Ocean \& Coastal Management, 109: 17-28.

[24] Dubois, D.; Prade, H. (1978). Operations on fuzzy numbers, International Journal of Systems Sciences, 9: 613-626.

[25] Van Laarhoven, P. J. M.; Pedrycz, W. (1983); A Fuzzy Extension of Saaty's Priority Theory, Fuzzy Sets and Systems, 11(3): 229-241.

[26] Likert, R. (1932); A Technique for the measurement of attitudes, Archives of Psychology, 140: $1-55$.

[27] Allen, E.; Seaman, C. A. (2007); Likert Scales and Data Analyses, Quality Progress, 40: 64-65.

[28] Chang, D.-Y. (1996); Applications of the extent analysis method on fuzzy AHP, European Journal of Operational Research, 95: 649-655.

[29] Zavadskas, E.K.; Turskis, Z.; Antucheviciene, J.; Zakarevicius, A. (2012); Optimization of weighted aggregated sum product assessment, Electronics and Electrical Engineering = Elektronika ir Elektrotechnika, 122(6): 3-6.

[30] Zavadskas, E.K.; Antucheviciene, J.; Hajiagha, S. H. R.; Hashemi, S. S. (2014); Extension of weighted aggregated sum product assessment with interval-valued intuitionistic fuzzy numbers (WASPAS-IVIF), Applied Soft Computing, 24: 1013-1021.

[31] Bagočius, V.; Zavadskas, E. K.; Turskis, Z. (2014); Multi-person selection of the best wind turbine based on the multi-criteria integrated additive-multiplicative utility function, Journal of Civil Engineering and Management, 20(4): 590-599.

[32] Hashemkhani Zolfani, S.; Aghdaie, M. H.; Derakhti, A.; Zavadskas, E.K.; Varzandeh, M.H.M. (2013); Decision making on business issues with foresight perspective; an application of new hybrid MCDM model in shopping mall locating, Expert Systems with Applications, 40: 7111-7121.

[33] Vafaeipour, M.; Hashemkhani Zolfani, S.; Varzandeh, M.H.M.; Derakhti, A.; Eshkalag, M.K. (2014); Assessment of regions priority for implementation of solar projects in Iran: New application of a hybrid multi - criteria decision making approach, Energy Conversion and Management, 86: 653-663.

[34] Zavadskas, E. K.; Antucheviciene, J.; Saparauskas, J.; Turskis, Z. (2013); MCDM methods WASPAS and MULTIMOORA: verification of robustness of methods when assessing alternative solutions, Economic Computation and Economic Cybernetics Studies and Research, 47(2): 5-20.

[35] Dëjus, T.; Antuchevičienè, J. (2013); Assessment of health and safety solutions at a construction site, Journal of Civil Engineering and Management, 19(5): 728-737.

[36] Šiožinytė, E.; Antuchevičienè, J. (2013); Solving the problems of daylighting and tradition continuity in a reconstructed vernacular building, Journal of Civil Engineering and Management, 19(6): 873-882. 
[37] Bitarafan, M.; Hashemkhani Zolfani, S.; Arefi, S.L.; Zavadskas, E.K.; Mahmoudzadeh, A. (2014); Evaluation of real-time intelligent sensors for structural health monitoring of bridges based on SWARA-WASPAS; a case in Iran, The Baltic Journal of Road and Bridge Engineering, 9(4): 333-340.

[38] Chakraborty, S.; Zavadskas, E.K. (2014); Applications of WASPAS method in manufacturing decision making, Informatica, 25(1): 1-20.

[39] Lashgari, S.; Antucheviciene, J.; Delavari, A; Kheirkhah, O. (2014); Using QSPM and WASPAS methods for determining outsourcing strategies, Journal of Business Economics and Management, 15(4): 729-743.

[40] Zavadskas, E. K.; Skibniewski, M. J.; Antucheviciene, J. (2014); Performance analysis of civil engineering journals based on the Web of Science database, Archives of Civil and Mechanical Engineering, 14(4): 519-527.

[41] MacCrimon, K. R. (1968); Decision Marking Among Multiple-Attribute Alternatives: A Survey and Consolidated Approach, RAND Memorandum, RM-4823-ARPA, The Rand Corporation, Santa Monica, Calif.

[42] Easton, A. (1973); One of a kind decisions involving weighted multiple objectives and disparate alternatives, in J. L. Cochrane and M. Zeleny (eds.), Multiple Criteria Decision Making, 657-667, University of South Carolina Press, Columbia, South Carolina. 